\title{
MicroRNAs as prognostic markers in indolent primary cutaneous B-cell lymphoma
}

Veronica Monsálvez ${ }^{1}$, Santiago Montes-Moreno ${ }^{2}$, María J Artiga ${ }^{3}$, Maria E Rodríguez ${ }^{2}$, Beatriz S Espiridión ${ }^{2}$, Maria Lozano ${ }^{2}$, Ricardo Fernández-de-Misa ${ }^{4}$, Jose L Rodríguez-Peralto ${ }^{5}$, Miguel A Piris ${ }^{2}$ and Pablo L Ortíz-Romero ${ }^{1}$

${ }^{1}$ Department of Dermatology, Hospital Universitario 12 de Octubre, Madrid, Spain; ${ }^{2}$ Departmen of Pathology, Hospital Universitario Marqués de Valdecilla/IFIMAV, Universidad de Cantabria, Santander, Spain;

${ }^{3}$ Tumor Bank Unit, Molecular Pathology Programme, Spanish National Cancer Center (CNIO), Madrid, Spain; ${ }^{4}$ Department of Dermatology, Hospital Universitario Nuestra Señora de Candelaria, Universidad de La Laguna, La Laguna, Spain and ${ }^{5}$ Department of Pathology, Hospital Universitario 12 de Octubre,

Madrid, Spain

Indolent primary cutaneous B-cell lymphoma is a group of malignant lymphomas comprising marginal zone B-cell lymphoma and centrofollicular B-cell lymphoma. Relapse rate of these tumors is close to $40 \%$, and identifying those patients who are likely to progress remains a challenge. The aim of this study was to characterize the microRNA (miRNA) expression profile of a series of primary cutaneous B-cell lymphomas and correlate with histological and clinical findings. We studied a series of 68 patients with primary cutaneous B-cell lymphomas ( 30 cutaneous marginal-zone B-cell lymphomas and 38 primary cutaneous centrofollicular lymphomas). A set of 11 miRNAs associated with the differentiation stage of $B$ cells was quantified by realtime PCR, using RNA extracted from formalin-fixed, paraffin-embedded tissue diagnostic samples. Relevant clinical variables were retrieved in a subset of 57 patients (28 cutaneous marginal zone B-cell lymphomas and 29 primary cutaneous centrofollicular lymphomas). miR-150 was upregulated in cutaneous marginal zone B-cell lymphomas relative to primary cutaneous centrofollicular lymphoma samples (false discovery rate $<0.05$ ). miR-155 and miR-150 expression levels were associated with progression-free survival in a univariate Cox regression analysis $(\boldsymbol{P}<\mathbf{0 . 1})$. After stratification by histological subtype, low-expression levels of miR-155 and miR-150 were both associated with shorter progression-free survival only in primary cutaneous marginal zone B-cell lymphomas cases (log-rank test, $P<0.05)$. In summary, miRNA expression analysis can be used as a tool for diagnosis and outcome prognosis in indolent primary cutaneous B-cell lymphoma.

Modern Pathology (2013) 26, 171-181; doi:10.1038/modpathol.2012.149; published online 31 August 2012

Keywords: cutaneous B-cell lymphoma; miRNAs; prognosis

Primary cutaneous B-cell lymphoma is a heterogeneous group of malignant lymphomas. Primary cutaneous B-cell lymphomas are the second most common group of extranodal lymphomas after mucosa-associated lymphoid tissue lymphomas of the gastrointestinal tract. The two most common disease entities in this group are primary cutaneous marginal zone B-cell lymphoma and primary cutaneous centrofollicular lymphoma. Leg-type cutaneous B-cell lymphoma is a less common type of

Correspondence: Dr S Montes-Moreno, MD, Department of Pathology, Hospital Universitario, Marqués de Valdecilla, IFIMAV, Santander, Spain.

E-mail: smontes@humv.es

Received 12 December 2011; revised 15 May 2012; accepted 15 May 2012; published online 31 August 2012 lymphoma in this location and has particular clinicopathological features that exclude it from the group of indolent cutaneous B-cell lymphomas.

Primary cutaneous marginal zone B-cell lymphoma is an indolent lymphoma composed of small B cells, including marginal zone (centrocyte-like) cells, lymphoplasmacytoid cells and plasma cells. Immunohistologically, the neoplastic marginal zone cells express CD20, CD79a and BCL2, and are negative for CD5, CD10 and BCL6. ${ }^{1,2}$ Primary cutaneous centrofollicular lymphoma is a tumor of neoplastic follicle center cells, with a mixture of centrocytes and centroblasts. Different growth patterns can be found, including purely follicular, mixed follicular and diffuse patterns, and a diffuse growth pattern. The neoplastic follicle center cells express CD20, CD79a and BCL6. CD10 is positive to 
a varying extent. Primary cutaneous centrofollicular lymphoma does not commonly express BCL2, MUM-1 or FOXP1. ${ }^{1-8}$

By definition, all these lymphomas are restricted to skin at the time of diagnosis, although in advanced phases, they may invade lymphatic nodes and bone marrow. Primary cutaneous marginal zone B-cell lymphoma and primary cutaneous centrofollicular lymphoma are both characterized by an indolent clinical course with relapse rates close to $40 \%{ }^{9}$ Clinical features such as TNM staging provide prognostic information only in the patients with leg-type primary cutaneous B-cell lymphoma and, overall, only the histological classification based on the WHO-EORTC guidelines, which include morphology and skin site, provides meaningful prognostic information. ${ }^{10-12}$ Thus, the early identification of patients who are likely to progress remains a challenge, especially for those cases with indolent histology (primary cutaneous marginal zone B-cell lymphoma and primary cutaneous centrofollicular lymphoma). ${ }^{10,13,14}$

MicroRNAs (miRNAs) have recently been identified as potential markers for diagnosis and prognosis in various solid and hematolymphoid neoplasms. ${ }^{15}$ miRNAs are small single-stranded, non-coding RNA molecules, about 22 nucleotides long, that regulate gene expression. ${ }^{16}$ It is estimated that miRNAs regulate $10-30 \%$ of all protein-coding genes. ${ }^{17}$ Over 700 miRNAs have been verified in humans, although recent studies have identified over 1000 miRNA species in human B cells. ${ }^{18}$

Various miRNAs are associated with particular normal B-cell differentiation stages. ${ }^{18-20}$ For example, miR-150 was first found to be expressed in mature B cells and to regulate B-cell differentiation by targeting the transcription factor c-Myb. ${ }^{21}$ miR-223 is overexpressed in naive and memory cells relative to germinal center cells. The expression of miR-223 in the naive stage was found to inhibit the expression of transcription factors, such as LMO2, that are expressed at high levels in non-neoplastic germinal center $\mathrm{B}$ cells. ${ }^{20}$ Other miRNAs are known to be overexpressed in the germinal center stage of differentiation, compared with either naive or memory $\mathrm{B}$ cells, ${ }^{18}$ including miR-17-5p and miR-155. Many of these miRNAs have been found to be deregulated in the neoplastic counterparts of these B cells. For example, the expression of miR-155 is stronger in some lymphoma types than in normal B cells. ${ }^{22-24}$

This study aimed to characterize the miRNA expression profile of a series of primary cutaneous B-cell lymphomas. On the basis of published data, ${ }^{18,20,25}$ we selected a set of 11 miRNAs known to be associated with a particular normal B-cell stage of differentiation. We evaluated their expression by RT-PCR in a cohort of 68 primary cutaneous B-cell lymphoma patients with formalin-fixed, paraffin embedded tissue available from the diagnostic sample. We found particular miRNA species to be associated with the histopathological diagnosis (primary cutaneous centrofollicular lymphoma vs primary cutaneous marginal zone B-cell lymphoma) and an miRNA signature related with clinical outcome (progression-free survival).

\section{Materials and methods}

\section{Patient Samples}

The study population consisted of a retrospective multi-institutional series of 68 cases of primary cutaneous B-cell lymphoma (30 cutaneous marginal zone B-cell lymphomas and 38 primary cutaneous centrofollicular lymphomas). Thirty-seven cases were retrieved from the cutaneous lymphoma registry of the dermatology service of Hospital 12 de Octubre (Madrid, Spain). Thirty-one further cases were retrieved from the Spanish National Cancer Center consultation files. A clinical data file was created to collate retrospectively all relevant clinical features included in subsequent analyses. We retrieved 57 complete clinical forms. This restricted set of 57 cases was used for statistical analysis in conjunction with the clinical variables. The current study was reviewed and approved as being of minimal/no risk or as exempt by each of the participating Institutional Review Boards (Hospital Universitario 12 de Octubre, Madrid and Carlos III Institutional Review Board).

\section{Histology and Immunohistochemistry}

All primary cutaneous B-cell lymphoma cases with available formalin-fixed, paraffin embedded tissue were histologically reviewed by a panel of hematopathologists (SMM, MAP; 68 cases). Immunohistochemical staining was performed following standard automated protocols using antibodies against CD20, BCL2, BCL6, CD10, $\kappa$ - and $\lambda$-light chains when required. All cases were classified according to the WHO Classification. ${ }^{26}$ Specific criteria for the distinction between primary cutaneous marginal zone lymphoma and primary cutaneous centrofollicular lymphoma included the following: the growth pattern (nodular, periadnexal, diffuse dermal), the composition of the neoplastic population (mixed centoblastic-centrocytic in centrofollicular lymphoma, polymorphic centrocytoid with plasma cell differentitation in marginal zone lymphoma), the relationship between the neoplastic population and follicular dendritic cells, the presence of reactive germinal centers in marginal zone lymphoma cases or, in contrast, a homogeneous presence of neoplastic follicles in centrofollicular lymphoma, and the positivity in the neoplastic population for BCL6, a germinal center-related protein in centrofollicular lymphoma cases. 
Table 1 Sequences of miRNAS studied in primary cutaneous lymphomas

\begin{tabular}{|c|c|c|}
\hline $\operatorname{miRNA}$ & Mature sequence (Homo sapiens; $5^{\prime}-3^{\prime}$ ) & Expresión in normal B cellas and/ir B-cell lymphomas \\
\hline miR-150 & UCUCCCAACCCUUGUACCAGUG & Lymph nodes and spleen in mature B-cell development ${ }^{1}$ \\
\hline miR-155 & UUAAUGCUAAUCGUGAUAGGGGU & Germinal center B cells ${ }^{2}$ \\
\hline miR-331 & CUAGGUAUGGUCCCAGGGAUCC & Germinal center B cells ${ }^{3}$ and diffuse large B-cell lymphomas ${ }^{4}$ \\
\hline $\operatorname{miR}-221$ & AGCUACAUUGUCUGCUGGGUUUC & Diffuse large B-cell lymphomas ${ }^{5}$ \\
\hline miR-222 & AGCUACAUCUGGCUACUGGGU & Plasma cells ${ }^{6}$ and diffuse large B-cell lymphomas ${ }^{7}$ \\
\hline miR-223 & UGUCAGUUUGUCAAAUACCCCA & Naive and plasma cells $s^{6,8}$ \\
\hline miR-15a & UAGCAGCACAUAAUGGUUUGUG & Plasma cells ${ }^{6}$ and chronic lymphocytic leukemia ${ }^{9}$ \\
\hline miR-16 & UAGCAGCACGUAAAUAUUGGCG & Chronic lymphocytic leukemia ${ }^{9}$ and diffuse B-cell lymphomas \\
\hline miR-17_5p & CAAAGUGCUUACAGUGCAGGUAG & Germinal center B cells ${ }^{6}$ \\
\hline miR-19a & UGUGCAAAUCUAUGCAAAACUGA & Naive B cells ${ }^{6}$ and diffuse large B-cell lymphomas ${ }^{5}$ \\
\hline miR-93 & CAAAGUGCUGUUCGUGCAGGUAG & Germinal center B cells and diffuse large B-cell lymphomas ${ }^{6}$ \\
\hline
\end{tabular}

We have studied 11 miRNAs according to the literature, based on the expression of these miRNAS in different stages of normal B-cell differentiation.

\section{RT-PCR for Relative miRNA Quantification Using RNA from Formalin-fixed, Paraffin-Eembedded Tissue}

After reviewing the published data, we selected 11 miRNAs to be quantified further by RT-PCR using RNA extracted from the diagnostic formalinfixed, paraffin embedded tissue sample. ${ }^{18,20}$ These miRNAs were selected according to the evidence regarding its association with particular stages of B-cell differentiation. We used commercial (Taqman) probes against miR-150, miR-155, miR331, miR-221, miR-222, miR-223, miR-15a, miR-16, miR-17, miR-19a and miR-93. Details of the quantified miRNA sequences are given in Table 1.

The miRNA expression in formalin-fixed, paraffin embedded tissues was analyzed using the Applied Biosystems 384-well multiplex RT-PCR assay with $250 \mathrm{ng}$ of total RNA. RNA from each case was reverse-transcribed in triplicate, using a multiplexlooped primer pool with the selected miRNA probes. Each completed reaction was loaded onto the 384-well plate and RT-PCR was done using the ABI 7900HT Prism. Two noncoding RNAs (RNU44 and RNU6b) were used as endogenous RNAs. ${ }^{27} \mathrm{Ct}$ values were exported using SDS software (version 2.3 ), and the data were analyzed with Real-Time StatMiner software (INTEGROMICS; http://www. integromics.com/StatMiner.php). An miRNA was considered to be present for values of $\mathrm{Ct}<26$ in all three biological replicates; $-\Delta \mathrm{Ct}$ values ( - (Ct value of miRNA of interest: mean Ct value for RNU44 and RNU6b)) were subjected to further statistical analysis.

\section{Microdissection}

We performed laser-capture microdissection using a Carl Zeiss Axio Observer Inverted Microscope coupled with Axio 4.6-Microbeam Palm software (version 4.6). We selected two cases with a high level of expression of miR-150, miR-155 and miR223 , and performed laser-capture microdissection to determine the cellular origin of the expression of these miRNAs. We performed RT-PCR following the previously described protocols for the selected miRNAs in five different compartments, identified either by morphology in hematoxylin and eosin sections (the epithelium, germinal center and extra germinal center cells) or by immunophenotype (CD20-positive and CD3-positive cells). We normalized the results using the expression between total number of cells of each compartment.

\section{Statistics}

Significantly differential expression of miRNA in histological subtypes was identified using the Student's $t$-test, which compares the mean expression of each miRNA. Corrections for multiple testing (using the false-discovery rate, FDR) were applied using the Pomelo $2^{28}$ tool.

To analyze the association between miRNA expression and survival, we first did a univariate Cox analysis to identify miRNAs related with progression-free survival ${ }^{29}$ (miRNA expression after RT-PCR was used as a continuous variable and significance was concluded for values of $P<0.1$ ). We then dichotomized the values of expression of the significant miRNAs (miR-150 and miR-155) and plotted Kaplan-Meier curves with progression-free survival as the outcome, examining their significance with the log-rank test. ${ }^{30}$ Cutaneous progression was defined according to the criteria by Senff et al. ${ }^{31}$ These analyses were done using SPSS version 15.0.0 (SPSS, Chicago, IL, USA).

\section{Results}

\section{Clinical Characteristics of the Series}

The clinical characteristics of the set of patients studied are summarized in Table 2.

Complete clinical data were available for 57 patients ( 25 female and 32 male). The median age 
Table 2 Summary of the clinical characteristics associated with histological type

\begin{tabular}{|c|c|c|c|}
\hline Characteristic & Total (\%) & $\begin{array}{c}\text { Primary } \\
\text { cutaneous } \\
\text { marginal } \\
\text { zone } \\
\text { B-cell lymphoma }\end{array}$ & $\begin{array}{l}\text { Primary } \\
\text { cutaneous } \\
\text { centro- } \\
\text { follicular } \\
\text { lymphomo }\end{array}$ \\
\hline Histology & 57 & $28(49 \%)$ & $29(51 \%)$ \\
\hline \multicolumn{4}{|l|}{ Sex } \\
\hline Female & $25(44)$ & $10(17 \%)$ & $15(26 \%)$ \\
\hline Male & $32(56)$ & $18(32 \%)$ & $14(25 \%)$ \\
\hline Age at diagnosis (mean) & 55 & 53 & 57 \\
\hline \multicolumn{4}{|l|}{ Stage at diagnosis ${ }^{\mathrm{a}}$} \\
\hline Localized (<T2cNoM0) & $46(80)$ & $23(40 \%)$ & $23(40 \%)$ \\
\hline Multifocal ( $\geq$ T2cNoM0) & $11(19)$ & $5(9 \%)$ & $6(10 \%)$ \\
\hline \multicolumn{4}{|c|}{ Maximum stage in the follow-up ${ }^{\mathrm{a}}$} \\
\hline Localized (<T2cNoM0) & $39(68)$ & $19(33 \%)$ & $20(35 \%)$ \\
\hline Multifocal ( $\geq$ T2cNoM0) & $18(36)$ & $9(16 \%)$ & $9(16 \%)$ \\
\hline Relapses $^{\mathrm{a}}$ & $22(39)$ & $10(45 \%)$ & $12(55 \%)$ \\
\hline Progression $^{\mathrm{a}}$ & $11(19)$ & $6(55 \%)$ & $5(45 \%)$ \\
\hline \multicolumn{4}{|l|}{ Locations } \\
\hline Head & $19(29)$ & 10 & 9 \\
\hline Scalp & $6(9)$ & 2 & 4 \\
\hline Trunk & $4(6)$ & 3 & 1 \\
\hline Arms & $27(41)$ & 13 & 14 \\
\hline Legs & $10(15)$ & 7 & 3 \\
\hline \multicolumn{4}{|l|}{ Number of lesions } \\
\hline 1 & $32(56)$ & 14 & 18 \\
\hline 2 to 4 & $22(39)$ & 14 & 8 \\
\hline 5 or more & $3(5)$ & 0 & 3 \\
\hline
\end{tabular}

Details related to sex, age at diagnosis, stage, maximum stage at follow-up and number of relapses and progressions are shown. Progression was considered in those cases with an increase in the disease stage after relapse. None of the clinical variables studied was associated with progression-free survival or overall survival in the univariate Cox regression analysis (data not shown). Location and number of lesions for each tumor type is given.

${ }^{\mathrm{a}}$ We did not find any significant differences between the histological subtypes for the clinical variables using Fisher's exact test. for all cases was 55 years (range, 23-87 years). In the set of cases for which clinical data were available, 28 cases were diagnosed as primary cutaneous marginal zone B-cell lymphomas and 29 were diagnosed as primary cutaneous centrofollicular lymphomas ${ }^{26}$ (Figure 1).

The median follow-up time for all cases of indolent primary cutaneous B-cell lymphoma was 46 months (range, 1-196 months). During follow-up, two patients died of causes unrelated to lymphoma. The median time until first recurrence was 19 months, whereas the average time until progression was 12 months (Table 3 ). There were 22 recurrences (39\% of the total number of cases), of which 10 were primary cutaneous marginal zone B-cell lymphomas $(45 \%)$ and 12 were primary cutaneous centrofollicular lymphomas $(55 \%)$. Eleven cases progressed $(19 \%$ of the total), of which six were primary cutaneous marginal zone B-cell lymphomas (55\%) and five were primary cutaneous centrofollicular lymphomas (46\%; $P$ log-rank for progression-free survival nonsignificant, according to histological subtype; Table 2). No case had systemic progression (lymph node involvement or extracutaneous metastases). Treatments received were as follows: surgery (32 cases), local radiotherapy (16 cases), intralesional rituximab (5 cases), topical or systemic steroids (4 cases) and chemotherapy (3 cases). Two cases did not receive any treatment. No information about treatment was available for four cases. In nine cases, two treatments were required to achieve an initial complete response, whereas the rest achieved this with the first treatment (Table 4).

The univariate Cox regression analysis did not reveal any significant differences in the outcome with respect to clinical features (sex, age, stage at diagnosis, maximum stage reached, data not a

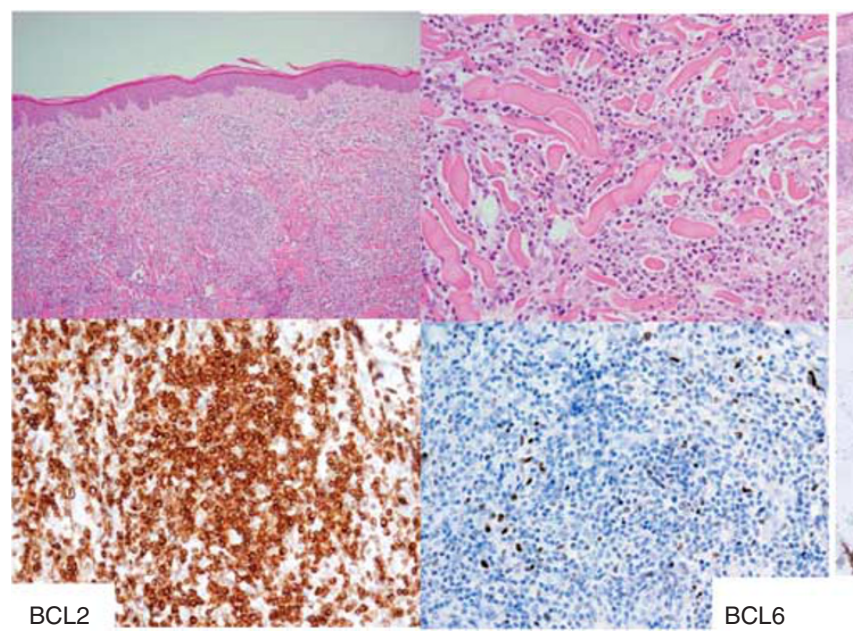

b

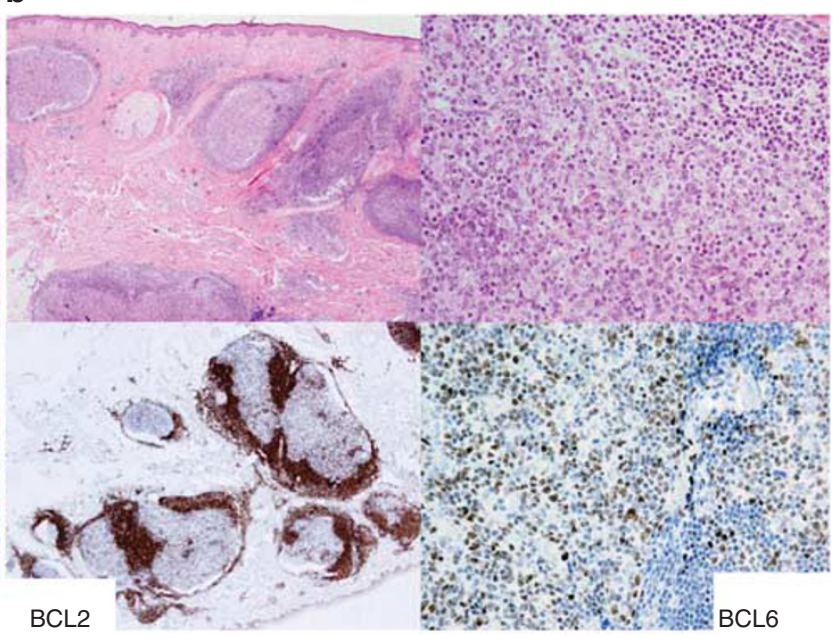

Figure 1 Histological features of primary cutaneous B-cell lymphomas. (a) Primary cutaneous marginal zone B-cell lymphomas is an indolent lymphoma composed of small B cells, including marginal zone (centrocyte-like), lymphoplasmacytoid and plasma cells. Immunohistologically, the neoplastic cells express CD20, CD79a and Bcl-2, and are negative BCL-6. (b) PCFCL is a tumor of neoplastic follicle center cells, with a mixture of centrocytes and centroblasts. Different growth patterns can be found, including purely follicular, mixed follicular and diffuse patterns, and a diffuse growth pattern. The neoplastic follicle center cells express CD20, CD79a and Bcl-6. PCFCL does not commonly expresses BCL-2. 
shown), nor did we find any significant differences between the histological subtypes for the clinical variables using Fisher's exact test (Table 2).

Table 3 Relapse rate and progression rate

\begin{tabular}{lccc}
\hline & $\begin{array}{c}\text { Primary } \\
\text { cutaneous } \\
\text { B-cell } \\
\text { lymphomas }\end{array}$ & $\begin{array}{c}\text { Primary } \\
\text { cutaneous } \\
\text { marginal zone } \\
\text { B-cell } \\
\text { lymphoma }\end{array}$ & $\begin{array}{c}\text { Primary } \\
\text { cutaneous } \\
\text { centrofollicular } \\
\text { lymphoma }\end{array}$ \\
\hline $\begin{array}{l}\text { Time to relapse } \\
\text { (mean, months) }\end{array}$ & 19 & 9 & 26 \\
$\begin{array}{l}\text { Time to } \\
\text { progression } \\
\text { (mean, months) }\end{array}$ & 12 & 9 & 15 \\
$\begin{array}{l}\text { Follow-up time } \\
\text { (mean, months) }\end{array}$ & 46 & 53 & 41 \\
\hline
\end{tabular}

Details regarding relapse and progression mean times are shown. No differences were found when comparing the progression rates according to the histological subtype.

\section{Different miRNA Expression Profiles in Primary Cutaneous Marginal Zone B-cell Lymphomas and Primary Cutaneous Centrofollicular Lymphomas}

We measured the expression of 11 miRNAs in the entire set of 68 primary cutaneous B-cell lymphoma cases. Of these, 30 cases were classified as primary cutaneous marginal zone B-cell lymphomas and 38 as primary cutaneous centrofollicular lymphomas. Only the expression of miR-150 differed significantly between the two groups $($ FDR $<0.1)$ (Figure 2); it was overexpressed in primary cutaneous marginal zone B-cell lymphomas relative to the average expression in primary cutaneous centrofollicular lymphomas. Although miR-223 was also upregulated in primary cutaneous marginal zone B-cell lymphomas compared with primary cutaneous centrofollicular lymphoma $(F D R=0.13)$, the association was not statistically significant.

Laser-capture microdissection of different cellular compartments in two cases of primary cutaneous marginal zone B-cell lymphomas confirmed that the

Table 4 Treatments

\begin{tabular}{|c|c|c|c|c|c|}
\hline Treatments & $\begin{array}{c}\text { Total } \\
\text { treatments } \\
(\%)\end{array}$ & $\begin{array}{c}\text { Primary cutaneous } \\
\text { marginal zone } \\
\text { lymphoma }\end{array}$ & $\begin{array}{l}\text { Complete } \\
\text { remission }\end{array}$ & $\begin{array}{l}\text { Primary cutaneous } \\
\text { centrofollicular } \\
\text { lymphoma }\end{array}$ & $\begin{array}{l}\text { Complete } \\
\text { remission }\end{array}$ \\
\hline Surgery & $32(56)$ & 19 & $79 \%(15 / 19)$ & 13 & $85 \%(11 / 13)$ \\
\hline Radiotherapy & $16(20)$ & 8 & $100 \%(8 / 8)$ & 8 & $88 \%(7 / 8)$ \\
\hline Rituximab IL & $5(9)$ & 8 & $100 \%(8 / 8)$ & 3 & $100 \%(3 / 3)$ \\
\hline Chemotherapy & $3(5)$ & 1 & $100 \%(1 / 1)$ & 2 & $100 \%(2 / 2)$ \\
\hline Steroids & $4(7)$ & 2 & $100 \%(2 / 2)$ & 2 & $50 \%(1 / 2)$ \\
\hline No treatments & $2(4)$ & 1 & $100 \%(1 / 1)$ & 2 & $100 \%(2 / 2)$ \\
\hline$>1$ treatment & $9(16)$ & $5(55,5 \%)$ & $100 \%(5 / 5)$ & $4(44,44 \%)$ & $100 \%(4 / 4)$ \\
\hline
\end{tabular}

Details regarding different treatments received.

\begin{tabular}{|c|c|c|c|c|}
\hline miR & $\begin{array}{c}\text { PRIMARY } \\
\text { CUTANEOUS } \\
\text { MARGINAL } \\
\text { ZONE B CELL } \\
\text { IYMPHOMA } \\
(30)\end{array}$ & $\begin{array}{c}\text { PRIMARY } \\
\text { CUTANEOUS } \\
\text { CENTRO- } \\
\text { FOLICULAR } \\
\text { IYMPHOMA } \\
(38)\end{array}$ & Unadj.p & FDR_indep \\
\hline & Mean expression & Mean expression & & \\
\hline mir150 & 5,2613 & 4,5477 & 0,0050 & 0,0552 \\
\hline mir223 & 3,7152 & 3,2908 & 0,0244 & 0,1347 \\
\hline mir93 &,- 0308 &, 2376 & 0,2137 & 0,6646 \\
\hline mir155 & 2,7541 & 3,1038 & 0,2417 & 0,6646 \\
\hline mir16 & 4,7705 & 4,6505 & 0,4114 & 0,7671 \\
\hline mir17_5p & $-2,2914$ & $-2,0292$ & 0,4184 & 0,7671 \\
\hline mir19a &,- 0749 &,- 0287 & 0,5820 & 0,9146 \\
\hline mir15a & $-3,1351$ & $-3,0808$ & 0,7299 & 0,9368 \\
\hline mi221 & $-2,9758$ & $-2,9312$ & 0,76811 & 0,9368 \\
\hline mir222 & $-1,3256$ & $-1,5195$ & 0,91576 & 0,9368 \\
\hline mir331 &,- 6681 &,- 6960 & 0,93675 & 0,9368 \\
\hline
\end{tabular}

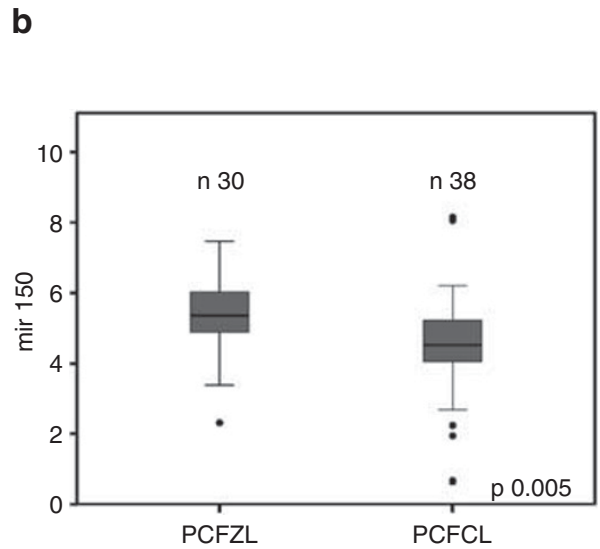

Figure 2 Differential expression of miRNAs in primary cutaneous marginal zone B-cell lymphomas and primary cutaneous centrofollicular lymphomas. (a) miR-150 was upregulated in primary cutaneous marginal zone B-cell lymphomas relative to primary cutaneous centrofollicular lymphomas samples (Student's $t$-test, $P<0.05$ and FDR $P<0.1$ ). A similar trend in miR-223 was not statistically significant (FDR $>0.1$ ), (b) Box-plot of miR-150 expression according to lymphoma type, revealed by RT-PCR. miR-150 is overexpressed in primary cutaneous marginal zone B-cell lymphomas relative to primary cutaneous centrofollicular lymphomas (Student's $t$-test, $P=0.005$ ). 
expression of miR-150, miR-155 and miR-223 arises mainly from the extra-germinal center compartment (including marginal zone and interstitial infiltrating components) and the CD20-positive cellular component. However, as expected, miR-150 expression was also found in the nonneoplastic CD3-positive T-cell component (Figure 3).

\section{Identification of miRNAs Associated with Outcome in Primary Cutaneous B-cell Lymphomas}

We investigated the association between miRNA expression and clinical outcome in the set of 57 cases patients for whom follow-up data were available. The relationship between the expression value of all the miRNAs studied and the clinical outcome (progression-free survival) were analyzed by univariate Cox regression. Only the continuous expression of miR-155 and miR-150 were related with progression-free survival $(P<0.1)$. Low-expression levels of miR-150 and miR-155 in the diagnostic sample were associated with increased risk of progression (shorter progression-free survival) in the whole series $(P<0.1$; Table 5a). After stratifying cases by histopathological diagnostic group (primary cutaneous marginal zone B-cell lymphomas (Table 5b) or primary cutaneous centrofollicular lymphoma (Table 5c), the association with progression-free survival remained statistically significant only for the primary cutaneous marginal zone B-cell lymphoma group and therefore, additional analyses were done only for this subgroup of cases. The equivalent analysis of the primary cutaneous centrofollicular lymphoma cases is shown in Figure 4. Median stratification of the continuous values of miR-150 and miR-155 expression grouped all patients as having low $(<$ median) or high ( $>$ median) miRNA levels.

a

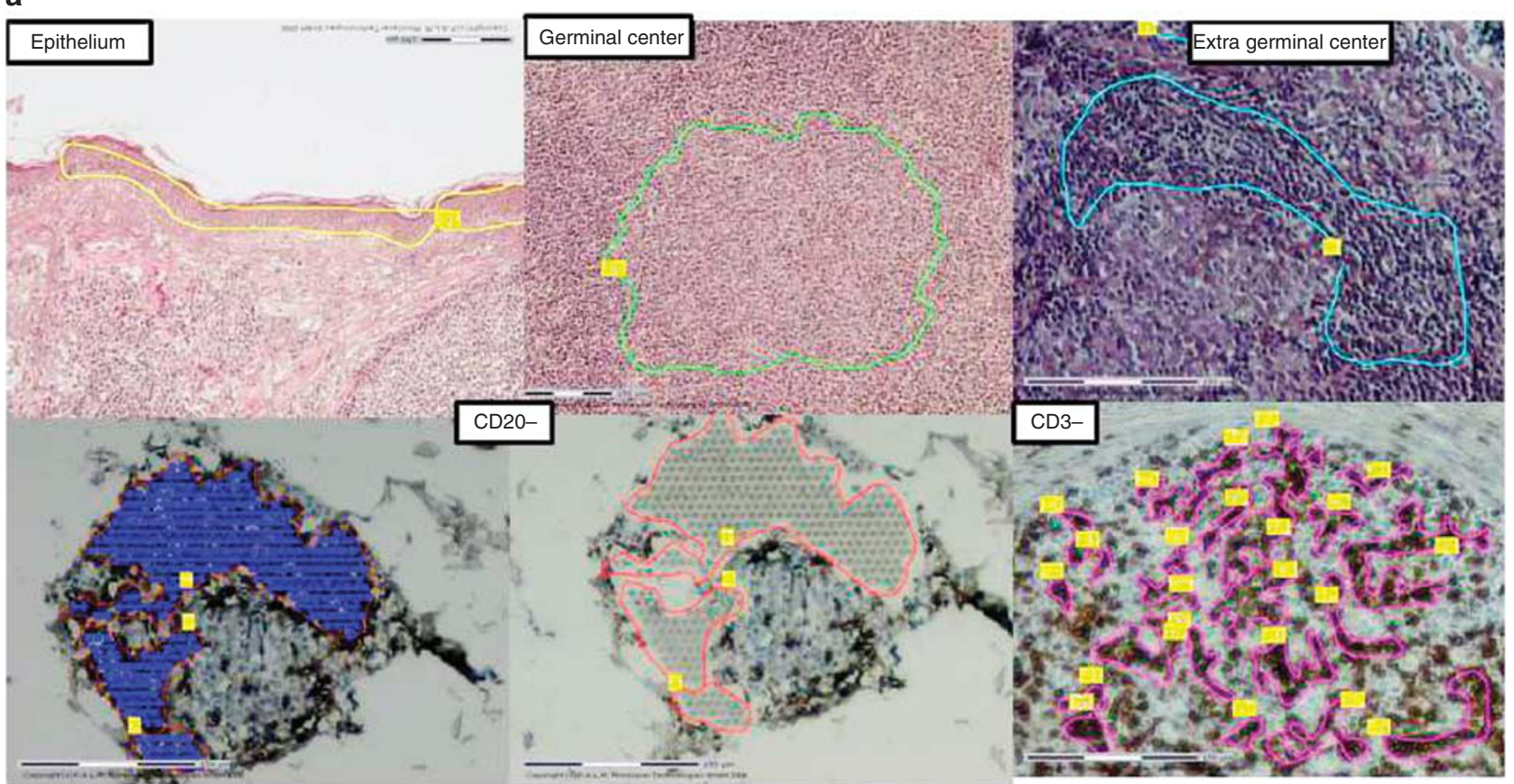

b

\begin{tabular}{|c|c|c|c|c|c|}
\hline Case & Origin cell & Number of cells & $\begin{array}{c}\text { miR150 } \\
\text { (normalized) }\end{array}$ & $\begin{array}{c}\text { miR155 } \\
\text { (normalized) }\end{array}$ & $\begin{array}{c}\text { miR223 } \\
\text { (normalized) }\end{array}$ \\
\hline MZL & Epithelium & 13568 & 0,29 & 0,23 & 0,20 \\
\hline MZL & Germinal center & 13290 & 0,26 & 0,19 & 0,15 \\
\hline MZL & Extra germinal center & 20574 & 0,40 & 0,19 & 0,13 \\
\hline MZL & CD20+ & 26788 & 0,29 & 0,27 & 0,20 \\
\hline MZL & CD3+ & 41457 & 0,15 & 0,05 & 0,03 \\
\hline
\end{tabular}

Figure 3 Cellular origin of miR-150, miR-155 and miR-223 after laser-capture microdisecction. (a) Histological microdissection images from five cellular compartments: epithelium, germinal centers and extra-germinal center. Bottom, CD20 + cells before and after microdissection; bottom right, CD3 + cells. (b) Results of microdissection, showing a predominance of miR-150 in the extra-germinal center and in CD20 + malignant cells, and also expression in CD3 + cells. miR-155 and miR-223 are also more strongly expressed in CD20 + neoplastic cells than in the other cell types. 
Table 5 Relative risk of progression according to miR150 and miR155 expression

\begin{tabular}{|c|c|c|c|c|}
\hline & \multirow[t]{2}{*}{ Relative risk } & \multicolumn{2}{|c|}{$95 . \%$ IC para $R R$} & \multirow[t]{2}{*}{$P$-values } \\
\hline & & Inferior & Superior & \\
\hline \multicolumn{5}{|c|}{ (a) Primary cutaneous B-cell lymphomas (57 cases) ${ }^{\mathrm{a}}$} \\
\hline mir-155 & 0.375 & 0.156 & 0.902 & 0.029 \\
\hline mir-150 & 0.727 & 0.503 & 1052 & 0.091 \\
\hline mir-15a & 0.801 & 0.437 & 1467 & 0.472 \\
\hline mir-16 & 0.651 & 0.223 & 1902 & 0.432 \\
\hline mir-17_5p & 0.662 & 0.349 & 1255 & 0.206 \\
\hline $\operatorname{mir}-19 \mathrm{a}$ & 0.554 & 0.200 & 1541 & 0.258 \\
\hline mir-93 & 0.792 & 0.386 & 1626 & 0.526 \\
\hline mir-221 & 1170 & 0.752 & 1819 & 0.486 \\
\hline mir-222 & 1145 & 0.684 & 1918 & 0.606 \\
\hline mir-223 & 0.690 & 0.365 & 1304 & 0.253 \\
\hline $\operatorname{mir}-331$ & 0.635 & 0.297 & 1357 & 0.241 \\
\hline \multicolumn{5}{|c|}{ (b) Primary cutaneous marginal zone lymphomas (28 cases) } \\
\hline mir-155 & 0.357 & 0.110 & 1161 & 0.087 \\
\hline mir-150 & 0.173 & 0.057 & 0.531 & 0.002 \\
\hline mir-15a & 0.700 & 0.248 & 1973 & 0.500 \\
\hline mir-16 & 0.662 & 0.155 & 2825 & 0.577 \\
\hline mir-17_5p & 0.687 & 0.295 & 1598 & 0.383 \\
\hline $\operatorname{mir}-19 a$ & 0.627 & 0.130 & 3009 & 0.559 \\
\hline mir-93 & 0.783 & 0.250 & 2454 & 0.675 \\
\hline $\operatorname{mir}-221$ & 1229 & 0.642 & 2355 & 0.534 \\
\hline mir-222 & 1079 & 0.495 & 2350 & 0.848 \\
\hline mir-223 & 0.398 & 0.125 & 1267 & 0.119 \\
\hline $\operatorname{mir}-331$ & 0.364 & 0.096 & 1376 & 0.136 \\
\hline \multicolumn{5}{|c|}{ (c) Primary cutaneous centrofollicular lymphomas $(29 \text { cases })^{\mathrm{C}}$} \\
\hline mir-155 & 0.477 & 0.128 & 1784 & 0.271 \\
\hline mir-150 & 0.974 & 0.553 & 1715 & 0.927 \\
\hline mir-15a & 0.902 & 0.409 & 1990 & 0.798 \\
\hline $\operatorname{mir}-16$ & 0.639 & 0.128 & 3.187 & 0.585 \\
\hline mir-17_5p & 0.676 & 0.253 & 1803 & 0.434 \\
\hline mir-19a & 0.476 & 0.121 & 1882 & 0.290 \\
\hline $\operatorname{mir}-93$ & 0.826 & 0.324 & 2108 & 0.690 \\
\hline mir-221 & 1111 & 0.598 & 2064 & 0.738 \\
\hline mir-222 & 1182 & 0.599 & 2334 & 0.630 \\
\hline mir-223 & 0.776 & 0.309 & 1948 & 0.589 \\
\hline mir-331 & 0.868 & 0.296 & 2540 & 0.796 \\
\hline
\end{tabular}

Abbreviation: RR, relative risk.

${ }^{\text {a RR }}$ of progression according to expression of each miRNA in all 57 cases. High miR-150 and miR-155 expression are significantly associated with a lower rate of progression.

${ }_{\mathrm{B} R}$ for each lymphoma type. miR-150 and miR-155 expression are significantly associated with a low rate of progression in the marginal zone B-cell lymphoma group.

${ }^{\mathrm{C}}$ miRNA expression shows no significant association in the centrofollicular B-cell lymphoma group.

The separation of these patients according to the expression of both miR-150 and miR-155 was positively correlated with progression-free survival (log-rank test, $P<0.05$ ) in all cases in the series (Figure 5a and $\mathrm{b}$ ) and in the primary cutaneous marginal zone B-cell lymphomas group, that is, low levels of expression were correlated with shorter progression-free survival (Figure 6a and b).

We also grouped patients into three classes: (1) those with low-expression levels of both miRNA-150 and miRNA-155 (14 patients); (2) patients with low levels of expression of either miR-150 or miR-155 (30 patients); and (3) patients with high levels of expression of both miRNAs (13 patients). Consistent with the previous results, those patients with low-expression levels of miR-150 and miR-155 had a worse outcome (14 cases with 7 progressions) than those with partial expression of either miRNA (4 out of 30 patients progressed), or those with high levels of both prognostic miRNAs (13 cases, none with progression; Figure 7a). Once again, this effect of miR-150 and miR-155 on the progression-free survival was associated with lymphoma type. Stratifying patients by primary cutaneous centrofollicular lymphoma and primary cutaneous marginal zone B-cell lymphoma groups showed that the loss of miR-150 and miR-155 identified patients with poor prognosis only in the primary cutaneous marginal zone B-cell lymphoma group $(P<0.01$; Figure $7 b$ ).

As none of the clinical variables studied (age, sex, TNM classification at diagnosis, maximum stage during follow-up) was related to progression-free survival or overall survival in the univariate Cox regression analysis (Table 5), we did not perform any multivariate analysis comparing miRNAs and clinical variables.

\section{Discussion}

miRNAs are non-coding RNAs that are emerging as markers for solid and hematological tumors. ${ }^{17,32-34}$ There is growing evidence of their roles in healthy and pathological states, and their association with particular differentiation states. This is particularly evident in the lymphoid lineage, in which miRNA expression is closely related to the different maturation steps of B-cell differentiation. ${ }^{18}$ Furthermore, there are many examples of their value as diagnostic and prognostic tools for many cancer types.

Despite the great increase in the number of studies of miRNAs in nodal non-Hodgkin lymphomas, few studies have examined miRNA expression in primary cutaneous lymphomas, so far having been studied only in primary cutaneous T-cell lymphomas (mycosis fungoides and Sezary syndrome). ${ }^{20,35-37}$ Currently, little is known about the miRNA expression profile of indolent primary cutaneous B-cell lymphoma. The apparent relationship between miRNA expression and cell differentiation stage prompted us to search for differential expression miRNA profiles among the primary cutaneous marginal zone B-cell lymphoma and primary cutaneous centrofollicular lymphoma histological subtypes. As other authors have described, there are a group of miRNAs that are expressed differently, which were selected to be analyzed. Cells from the germinal center compartment are characterized by expression of miR331, ${ }^{25}$ miR93 and miR17-5p, ${ }^{18}$ meanwhile miR223 is not expressed. Naive B and plasma cells express miR223. ${ }^{18}$ Other miRNAs selected to be analyzed, such as miR221 and 
a

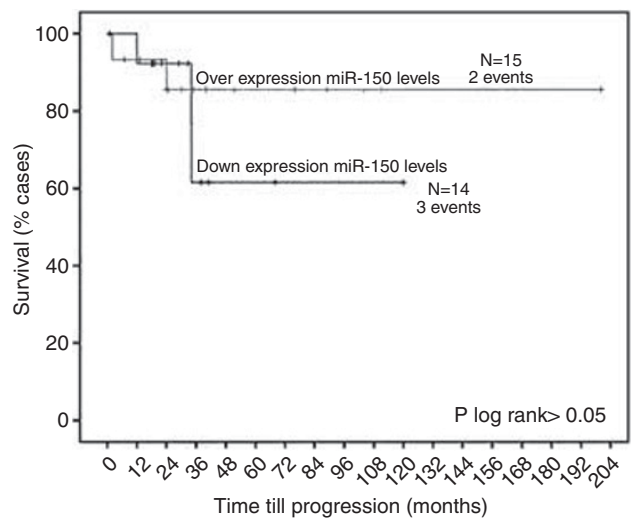

b Primary cutaneous centrofollicular lymphoma miR-155

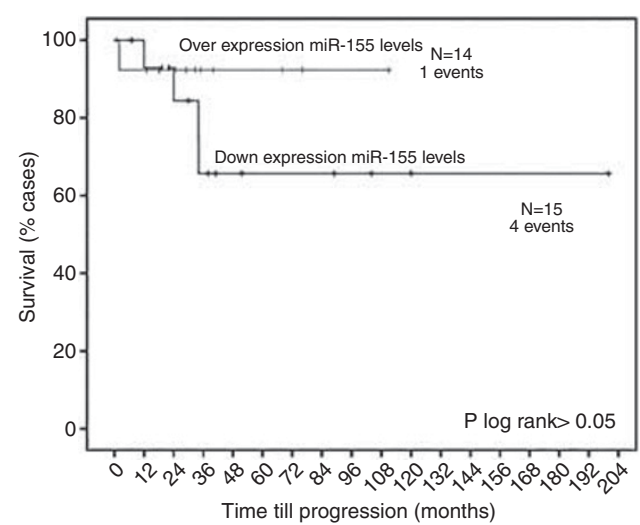

Figure 4 Progression-free survival with respect to expression of miR-150 and miR-155 in primary cutaneous centrofollicular lymphomas. Kaplan-Meier curves of progression-free survival for (a) miR-150 and (b) miR-155 in primary cutaneous centrofollicular lymphomas. Cases were stratified with respect to expression above or below the median. Neither miR-150 nor miR-155 expression is correlated with progression-free survival in primary cutaneous centrofollicular lymphoma.
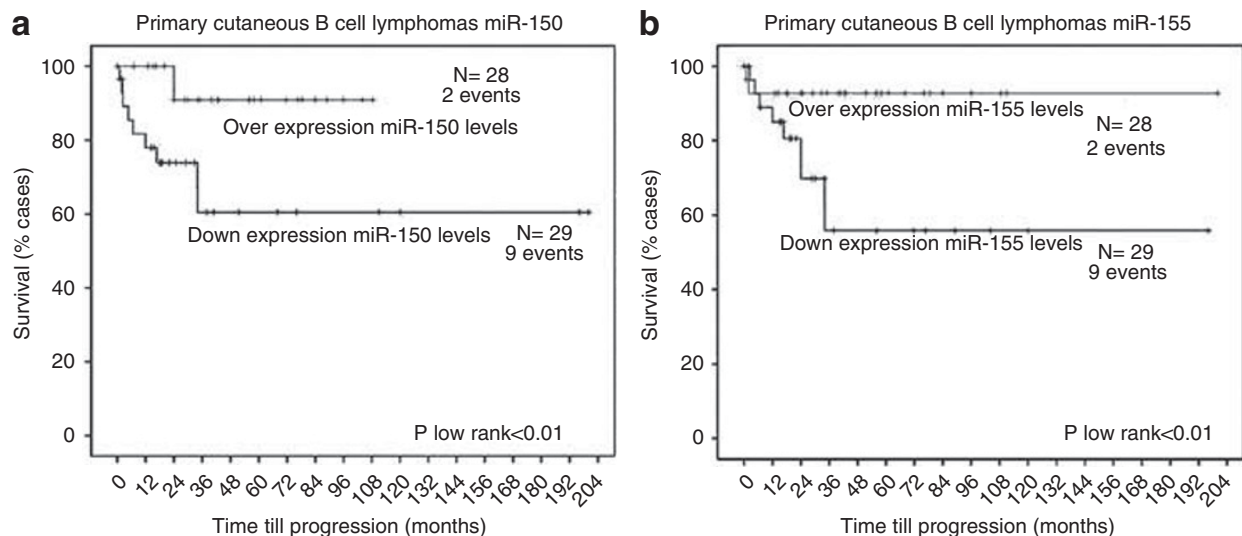

Figure 5 miR-150 and miR-155 expression is related with progression-free survival of patients with indolent primary cutaneous B-cell lymphomas. Kaplan-Meier estimates for 57 patients with indolent primary cutaneous B-cell lymohomas with respect to (a) miR-150 and (b) miR-155 expression. For both miRNAs, cases with levels of expression above the median have a better outcome than those with a low level of expression.
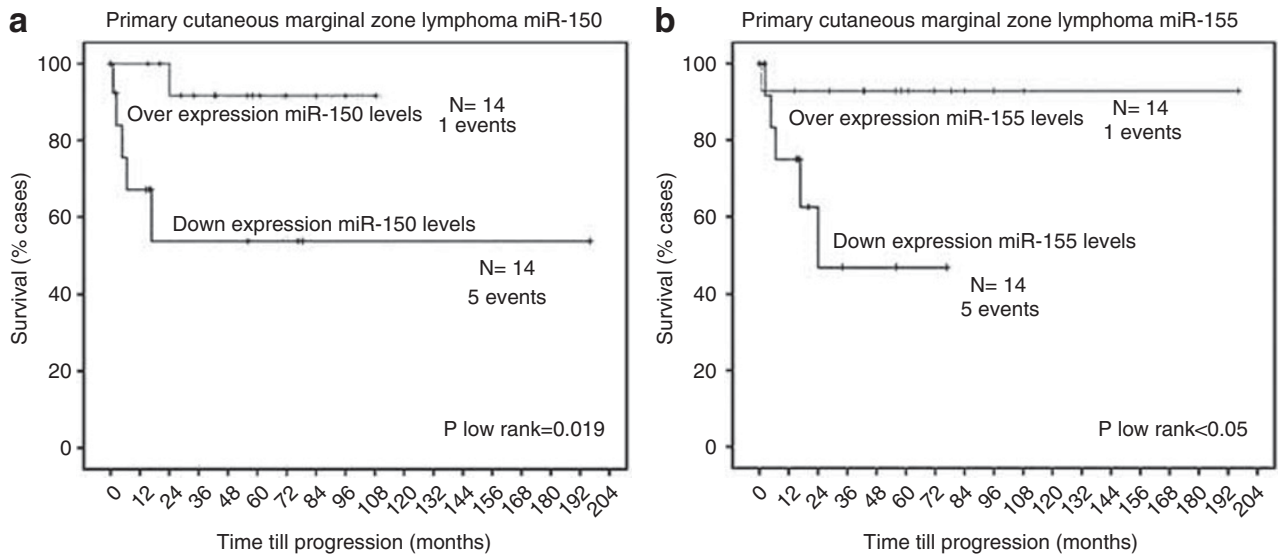

Figure 6 miR-150 and miR-155 expression affect the progression-free survival of patients with primary cutaneous marginal zone B-cell lymphomas. Kaplan-Meier estimates for 28 patients with primary cutaneous marginal zone B-cell lymphomas with respect to (c) miR-150 and (d) miR-155 expression. For both miRNAs, cases with levels of expression above the median have a better outcome than those with a low level of expression. 

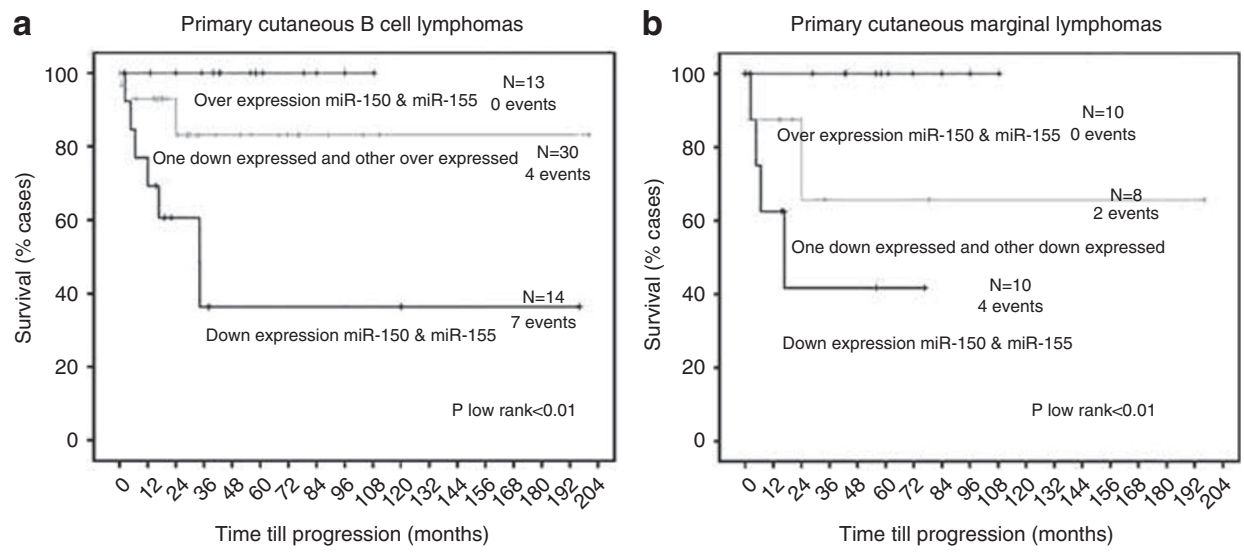

Figure 7 A combined model with both miR-150 and mi155 predicts progression-free survival in primary cutaneous marginal zone B-cell lymphomas. (a) Cases were stratified into three groups: (1) those with low-expression levels of miR-150 and miR-155; (2) patients with low-expression levels of either miR-150 or miR-155; (3) patients with high levels of expression of both miRNAs. Group 1 patients had a poorer outcome than those in groups 2 and 3 (left). (b) The effect of miR-150 and miR-155 on the progression-free survival is dependent on lymphoma type. Stratifying patients by PCFCL and primary cutaneous marginal zone B-cell lymphomas revealed that the loss of miR-150 and miR-155 identified patients with poor prognosis in the primary cutaneous marginal zone B-cell lymphomas group $(P<0.01)$, but not in the PCFCL group $(P>0.05)$.

miR222, ${ }^{25}$ are expressed in activated diffuse large B cell lymphomas. Furthermore, as clinical and pathological features are of weak prognostic value in this particular group of patients (except for Legtype diffuse large B-cell lymphomas), we hypothesized that miRNAs could be molecular markers for disease progression in this group of patients.

Here we have shown that miR150 is overexpressed in the primary cutaneous marginal zone B-cell lymphoma histological type when compared with primary cutaneous centrofollicular lymphoma type. Laser-capture microdissection revealed that miR-150 expression is derived mainly from the extra-germinal center cell compartment, with lower expression levels in germinal center cells. These results suggest that miR-150 expression levels in primary cutaneous marginal zone B-cell lymphomas may be at least partially related to the presence of a post-germinal center differentiation stage with few germinal center cells within the tumors. As miR-150 was also found to be expressed by non-neoplastic T cells in the microenvironment (although at lower levels than in CD20-positive B cells), we can also hypothesize that changes in the expression of this miRNA may also reflect, at least partially, changes in the T-cell microenvironmental compartment. miR-150 is expressed in mature B and T cells ${ }^{38}$ in lymph nodes and spleen. Xiao et $a l^{21}$ found that miR-150 controls the expression of the transcription factor c-Myb. It is downregulated in B-cell lymphoma cases such as Burkitt lymphoma and diffuse large B-cell lymphomas relative to non-neoplastic B cells. ${ }^{39,40}$ This observation has been confirmed by Lawrie $^{41}$ who showed that miR-150 is downregulated in diffuse large B-cell lymphoma cells compared with normal B cells. ${ }^{42}$

RT-PCR using RNA obtained from the diagnostic formalin-fixed, paraffin embedded tissue sample also showed that the low-expression levels of certain miRNAs at diagnosis are associated with an increased risk of progression. The low levels of miR-155 and miR-150 are correlated with a greater tendency to have a cutaneous progression during follow-up. This effect on prognosis is restricted to primary cutaneous marginal zone B-cell lymphoma cases, at least in this series of cases. After histopathological review of the primary cutaneous marginal zone B-cell lymphoma cases with altered miRNA levels, we did not see any particular difference in the histopathological features. Thus, miRNA quantification can have an additional role to histopathology in risk stratification for these patients with primary cutaneous marginal zone B-cell lymphoma.

miR-155 is involved in regulating the immune system, specifically by controlling T-cell differentiation $^{43}$ and B-cell maturation. ${ }^{44,45}$ miR-155 is required for regulating B-cell responses to thymusdependent and thymus-independent antigens, and at least, part of its effect is due to the direct regulation of PU.1 protein levels. ${ }^{44}$ miR-155 also has a tumor-suppressor role by which potentially oncogenic translocations generated by AID are reduced. ${ }^{46-48}$

Information about the prognostic impact of miR-155 expression in other lymphoma types is limited. No significant relationship has been found with diffuse large B-cell lymphomas outcome or overall survival. ${ }^{4,50}$ It seems clear that this miRNA is mainly overexpressed in patients with activated B-cell type diffuse large B-cell lymphomas, where, surprisingly, it is associated with a better outcome. ${ }^{49}$ These findings are in keeping with our results that identify miR-155 expression as a marker of better outcome (longer progression-free survival) in primary cutaneous B-cell lymphomas (marginal 
zone lymphoma-type). The causes of such an association are unclear, but may be associated with the regulatory role of miR-155 in oncogenic pathways such as NF- $\kappa \mathrm{B}$ (IkBKe), PI3KCA, or mutagenic elements such as AID. ${ }^{51,52}$ We also found miR-150 downregulation to be associated with shorter progression-free survival and a greater likelihood of cutaneous progression. As shown before, we also found differentially expressed levels of miR-150 between primary cutaneous marginal zone B-cell lymphomas and primary cutaneous centrofollicular lymphomas that might be partially related to the distinct stage of differentiation found in these tumors and the relative percentage of non-neoplastic T cells in the microenvironmental compartment. Additional studies are needed to determine whether changes in the non-neoplastic component affect outcome.

In summary, we have found that certain miRNA species, in particular miR-155 and miR-150, may be of prognostic value in patients with indolent primary cutaneous B-cell lymphoma, especially those of primary cutaneous marginal zone B-cell lymphoma type. The expression levels of these miRNAs can be measured easily using RNA extracted from the diagnostic formalin-fixed, paraffin embedded tissue. The loss of expression of these miRNAs is associated with a worse outcome. The mechanisms underlying this effect need to be clarified.

\section{Acknowledgements}

This study was supported by grants from the Ministerio de Sanidad y Consumo (PI051623, PI052800, CP06/00002, FISH 08/0856, RTICC), the Asociación Española contra el Cancer (AECC) and the Ministerio de Ciencia e Innovación (SAF 200803871), Spain. We acknowledge the Hospital 12 de Octubre Biobank office and the Spanish National Biobank Net Office at the Spanih National cancer Center for their skillful retrieval of clinical samples and data handling.

\section{Disclosure/conflict of interest}

The authors have no conflict of interest.

\section{Author-contributions}

V Monsálvez and S Montes-Moreno designed and performed the research, analyzed data and wrote the manuscript; ME Rodríguez and M Lozano performed the research; B Sánchez Espiridión performed the research and analyzed data; MJ Artiga retrieved clinical data and samples; R Fernández de Misa and JL Rodríguez-Peralto contributed clinical data; MA Piris designed research and wrote the manuscript; and PL Ortíz-Romero designed research, contributed clinical data and wrote the manuscript.

\section{References}

1 de Leval L, Harris NL, Longtine J, et al. Cutaneous b-cell lymphomas of follicular and marginal zone types: use of Bcl-6, CD10, Bcl-2, and CD21 in differential diagnosis and classification. Am J Surg Pathol 2001;25:732-741.

2 Hoefnagel JJ, Vermeer MH, Jansen PM, et al. Bcl-6 and CD10 expression in cutaneous B-cell lymphoma: further support for a follicle centre cell origin and differential diagnostic significance. Br J Dermatol 2003;149:1183-1191.

3 Hoefnagel JJ, Dijkman R, Basso K, et al. Distinct types of primary cutaneous large B-cell lymphoma identified by gene expression profiling. Blood 2005;105: 3671-3678.

4 Cerroni L, Volkenandt M, Rieger E, et al. bcl-2 protein expression and correlation with the interchromosomal $14 ; 18$ translocation in cutaneous lymphomas and pseudolymphomas. J Invest Dermatol 1994;102:231-235.

5 Alizadeh AA, Eisen MB, Davis RE, et al. Distinct types of diffuse large B-cell lymphoma identified by gene expression profiling. Nature 2000;403:503-511.

6 Cerroni L, Arzberger E, Putz B, et al. Primary cutaneous follicle center cell lymphoma with follicular growth pattern. Blood 2000;95:3922-3928.

7 Geelen FA, Vermeer MH, Meijer CJ, et al. Bcl-2 protein expression in primary cutaneous large B-cell lymphoma is site-related. J Clin Oncol 1998;16: 2080-2085.

8 Goodlad JR, Krajewski AS, Batstone PJ, et al. Primary cutaneous follicular lymphoma: a clinicopathologic and molecular study of 16 cases in support of a distinct entity. Am J Surg Pathol 2002;26:733-741.

9 Senff NJ, Noordijk EM, Kim YH, et al. European Organization for Research and Treatment of Cancer and International Society for Cutaneous Lymphoma consensus recommendations for the management of cutaneous B-cell lymphomas. Blood 2008;112:1600-1609.

10 Smith BD, Smith GL, Cooper DL, et al. The cutaneous B-cell lymphoma prognostic index: a novel prognostic index derived from a population-based registry. J Clin Oncol 2005;23:3390-3395.

11 Golling P, Cozzio A, Dummer R, et al. Primary cutaneous B-cell lymphomas-clinicopathological, prognostic and therapeutic characterisation of 54 cases according to the WHO-EORTC classification and the ISCL/EORTC TNM classification system for primary cutaneous lymphomas other than mycosis fungoides and Sezary syndrome. Leuk Lymphoma 2008;49: 1094-1103.

12 Gerami P, Wickless SC, Rosen S, et al. Applying the new TNM classification system for primary cutaneous lymphomas other than mycosis fungoides and Sezary syndrome in primary cutaneous marginal zone lymphoma. J Am Acad Dermatol 2008;59:245-254.

13 Kodama K, Massone C, Chott A, et al. Primary cutaneous large B-cell lymphomas: clinicopathologic features, classification, and prognostic factors in a large series of patients. Blood 2005;106:2491-2497.

14 Mian M, Marcheselli L, Luminari S, et al. CLIPI: a new prognostic index for indolent cutaneous B cell lymphoma proposed by the International Extranodal Lymphoma Study Group (IELSG 11). Ann Hematol 2010;90:401-408.

15 Zhang B, Pan X, Cobb GP, et al. microRNAs as oncogenes and tumor suppressors. Dev Biol 2007;302:1-12. 
16 Hammond SM. RNAi, microRNAs, and human disease. Cancer Chemother Pharmacol 2006;58 (Suppl 1):s63-s68.

17 Paranjape T, Slack FJ, Weidhaas JB. MicroRNAs: tools for cancer diagnostics. Gut 2009;58:1546-1554.

18 Jima DD, Zhang J, Jacobs C, et al. Deep sequencing of the small RNA transcriptome of normal and malignant human B cells identifies hundreds of novel microRNAs. Blood 2010;116:e118-127.

19 Malumbres R, Sarosiek KA, Cubedo E, et al. Differentiation stage-specific expression of microRNAs in B lymphocytes and diffuse large B-cell lymphomas. Blood 2009;113:3754-3764.

20 Zhang J, Jima DD, Jacobs C, et al. Patterns of microRNA expression characterize stages of human B-cell differentiation. Blood 2009;113:4586-4594.

21 Xiao C, Calado DP, Galler G, et al. MiR-150 controls B cell differentiation by targeting the transcription factor c-Myb. Cell 2007;131:146-159.

22 Eis PS, Tam W, Sun L, et al. Accumulation of miR-155 and BIC RNA in human B cell lymphomas. Proc Natl Acad Sci USA 2005;102:3627-3632.

23 Metzler M, Wilda M, Busch K, et al. High expression of precursor microRNA-155/BIC RNA in children with Burkitt lymphoma. Genes Chromosomes Cancer 2004;39:167-169.

24 Kluiver J, Poppema S, de Jong D, et al. BIC and miR-155 are highly expressed in Hodgkin, primary mediastinal and diffuse large $B$ cell lymphomas. J Pathol 2005;207:243-249.

25 Montes-Moreno S, Martinez N, Sanchez-Espiridion B, et al. miRNA expression in diffuse large B-cell lymphoma treated with chemoimmunotherapy. Blood 2011;118:1034-1040.

26 Willenze R, Swerdlow SH, Harris NL, Verqier B. Primary cutaneous follicle centre lymphoma. In: Swerdlow SH, Campo E, Harris NL, Jaffe ES, Pileri SA, Stein H, Thiele J, Vardiman JW (eds). WHO Classification of Tumors of Haematopoietic and Lymphoid Tissues; 4th edn, IARC: Lyon, France, 2008, pp 227-228.

27 Davoren PA, McNeill RE, Lowery AJ, et al. Identification of suitable endogenous control genes for microRNA gene expression analysis in human breast cancer. BMC Mol Biol 2008;9:76.

28 Morrissey ER, Diaz-Uriarte R. Pomelo II: finding differentially expressed genes. Nucleic Acids Res 2009;37:W581-W586.

29 Cheson BD, Pfistner B, Juweid ME, et al. Revised response criteria for malignant lymphoma. J Clin Oncol 2007;25:579-586.

30 Peto R, Pike MC, Armitage P, et al. Design and analysis of randomized clinical trials requiring prolonged observation of each patient. I. Introduction and design. Br J Cancer 1976;34:585-612.

31 Senff NJ, Willemze R. The applicability and prognostic value of the new TNM classification system for primary cutaneous lymphomas other than mycosis fungoides and Sezary syndrome: results on a large cohort of primary cutaneous B-cell lymphomas and comparison with the system used by the Dutch Cutaneous Lymphoma Group. Br J Dermatol 2007;157:1205-1211.

32 He L, Thomson JM, Hemann MT, et al. A microRNA polycistron as a potential human oncogene. Nature 2005;435:828-833.

33 Lawrie CH, Saunders NJ, Soneji S, et al. MicroRNA expression in lymphocyte development and malignancy. Leukemia 2008;22:1440-1446.
34 Iorio MV, Ferracin M, Liu CG, et al. MicroRNA gene expression deregulation in human breast cancer. Cancer Res 2005;65:7065-7070.

35 van der Fits L, van Kester MS, Qin Y, et al. MicroRNA21 expression in CD4 + T cells is regulated by STAT3 and is pathologically involved in Sezary syndrome. J Invest Dermatol 2011;131:762-768.

36 Ballabio E, Mitchell T, van Kester MS, et al. MicroRNA expression in Sezary syndrome: identification, function, and diagnostic potential. Blood 2010;116: 1105-1113.

37 van Kester MS, Ballabio E, Benner MF, et al. miRNA expression profiling of mycosis fungoides. Mol Oncol 2011;5:273-280.

38 Zhou B, Wang S, Mayr C, et al. miR-150, a microRNA expressed in mature B and T cells, blocks early B cell development when expressed prematurely. Proc Natl Acad Sci USA 2007;104:7080-7085.

39 Lawrie CH, Shilling R, Troussard X, et al. Expression profiling of persistent polyclonal B-cell lymphocytosis suggests constitutive expression of the AP-1 transcription complex and downregulation of Fas-apoptotic and TGFbeta signalling pathways. Leukemia 2009;23: 581-583.

40 Landgraf P, Rusu M, Sheridan R, et al. A mammalian microRNA expression atlas based on small RNA library sequencing. Cell 2007;129:1401-1414.

41 Lawrie CH. MicroRNA expression in lymphoid malignancies: new hope for diagnosis and therapy? J Cell Mol Med 2008;12:1432-1444.

42 Lawrie $\mathrm{CH}$, Chi J, Taylor S, et al. Expression of microRNAs in diffuse large $B$ cell lymphoma is associated with immunophenotype, survival and transformation from follicular lymphoma. J Cell Mol Med 2009;13:1248-1260.

43 Yin Q, Wang X, McBride J, et al. B-cell receptor activation induces BIC/miR-155 expression through a conserved AP-1 element. J Biol Chem 2008;283: 2654-2662.

44 Vigorito E, Perks KL, Abreu-Goodger C, et al. MicroRNA155 regulates the generation of immunoglobulin class-switched plasma cells. Immunity 2007;27:847-859.

45 Thai TH, Calado DP, Casola S, et al. Regulation of the germinal center response by microRNA-155. Science 2007;316:604-608.

46 Dorsett Y, McBride KM, Jankovic M, et al. MicroRNA-155 suppresses activation-induced cytidine deaminase-mediated Myc-Igh translocation. Immunity 2008;28:630-638.

47 Teng G HP, Landgraff P, Rice A, et al. Micro-RNA-155 is a negative regulator of activation-induced cytidine deaminase. Immunity 2008;28:621-629.

48 de Yebenes VG, Belver L, Pisano DG, et al. miR-181b negatively regulates activation-induced cytidine deaminase in B cells. J Exp Med 2008;205:2199-2206.

49 Jung I, Aguiar RC. MicroRNA-155 expression and outcome in diffuse large B-cell lymphomaBr J Haematol 2009;144:138-140.

50 Roehle A, Hoefig KP, Repsilber D, et al. MicroRNA signatures characterize diffuse large B-cell lymphomas and follicular lymphomas. Br J Haematol 2008; 142:732-744.

51 Desiderio S. Along came a spider: AID escapes a microRNA web. Immunity 2008;28:596-598.

52 Gottwein E, Mukherjee N, Sachse C, et al. A viral microRNA functions as an orthologue of cellular miR-155. Nature 2007;450:1096-1099. 